\title{
PRENATAL AND NEONATAL VARIABLES ASSOCIATED WITH ENAMEL HYPOPLASIA IN DECIDUOUS TEETH IN LOW BIRTH WEIGHT PRETERM INFANTS
}

\author{
Kátia Maria Dmytraczenko FRANCOํㅗㅇ, Sérgio Roberto Peres LINE², Maria Valeriana Leme de MOURA-RIBEIRO³
}

1- DDS, Graduate student, Department of Neurology, Medical School, State University of Campinas, Campinas, SP, Brazil.

2- DDS, MSc, PhD, Professor, Department of Morphology, Dental School of Piracicaba, State University of Campinas, Piracicaba, SP, Brazil.

3- MD, MSc, PhD, Associate Professor, Department of Neurology, Medical School, State University of Campinas, Campinas, SP, Brazil.

Corresponding address: Prof. Dr. Sérgio Roberto Peres Line - Faculdade de Odontologia de Piracicaba, UNICAMP - Departamento de Morfologia - Av. Limeira 901, 13414-901, Piracicaba, SP, Brasil - Phone: +55-19-2106-5333. - e-mail: serglin@fop.unicamp.br

Received: March 3, 2007 - Modification: July 23, 2007 - Accepted: October 2, 2007

\begin{abstract}
$T_{\text {his }}$

$T_{\text {his study investigated possible prenatal and neonatal variables that may influence the prevalence of tooth enamel hypoplasia }}$ in preterm and low birth weight children (LBW) and a matched control group of term children with normal birth weight (NBW). The study sample consisted of 61 children born preterm and with LBW examined at 18-34 months of age. The control group was formed by 61 infants born full term and with NBW examined at 31-35 months of age. All children were born at the Center of Integrated Attention of Women's Health (CAISM-UNICAMP). FDI criteria were followed for dental examination. Medical data was collected retrospectively from hospital records. Among preterms, $57.4 \%$ had some type of developmental defects of enamel (DDE), $52.5 \%$ had opacities and $21.3 \%$ presented hypoplasia. Among full-term children, 24.6\% presented DDE, 24.6\% had opacities and 3.3\% had hypoplasia. LBW preterm infants presented a higher prevalence of hypoplasia than NBW controls. The deciduous teeth most affected by hypoplasia were maxillary incisors. There was no significant association with prenatal variables; among neonatal variables there was a significant association with respiratory distress syndrome and neurological examination at discharge with an altered result.
\end{abstract}

Uniterms: Dental enamel hypoplasia; Deciduous tooth; Preterm birth; Low birth weight.

\section{INTRODUCTION}

Developmental defects of enamel (DDE) can be defined as alterations of dental enamel that result from several disturbances during amelogenesis ${ }^{7}$. Since dental enamel does not remodel, the defects that occur during its formation will be permanently recorded on tooth surface ${ }^{1}$. According to their clinical appearance, DDE can be classified into demarcated opacity, diffuse opacity and hypoplasia? Opacity is a qualitative defect involving an alteration in translucency of enamel and may present a white, yellow or brown color. It can be classified as demarcated or diffuse opacity. Hypoplasia is a quantitative defect associated with a reduced thickness of enamel.

DDE, especially hypoplasia, are clinically important since they can result in increased caries risk, dental sensitivity, increased tooth wear as well as esthetic implications ${ }^{12,13,14,20,21}$.

Previous studies have described a higher prevalence of DDE in children born preterm, with low birth weight (LBW, $<2,500$ g) and very low birth weight children (VLBW, $<1500$ g $)^{1,11,15,18}$. A frequency of $35 \%$ was reported in a descriptive Brazilian study with preterm infants ${ }^{4}$. In a cohort of healthy children, the prevalence rate for hypoplasia was $6 \%$ and $27 \%$ for opacities ${ }^{21}$. A Brazilian epidemiological study reported a prevalence of $24.4 \%$ for DDE and $11.1 \%$ for enamel hypoplasia in primary dentition of pre-school children ${ }^{12}$. The prevalence rates vary considerably due to differences in methods, such as the teeth examined, age at examination, diagnose criteria and whether hypoplasia and/or opacities were included.

DDE in deciduous teeth have been described in prematurity, low birth weight, respiratory distress syndrome, malnutrition, mineral deficiencies, hypocalcemic conditions, hyperbilirubinemia, infections during fetal life and neonatal period and after local traumatic injury by laryngoscopy and endotracheal intubation ${ }^{1,8,9,10,16,17,19}$.

Preterm is defined as a neonate whose birth occurred before 37 completed weeks (less than 259days) of gestation. Term is defined as a neonate born from 37 completed weeks to less than 42 completed weeks (259 to 293 days) of gestation $^{22}$. 
The purpose of this study was to investigate possible prenatal and neonatal variables that may influence the prevalence of enamel hypoplasia in preterm and low birth weight children and a matched control group of term children with normal birth weight (NBW).

\section{MATERIALAND METHODS}

\section{Patient Selection and Study Design}

All children included in this retrospective cohort study were born at the Center of Integrated Attention of Women's Health (CAISM-UNICAMP), between January, 2002 and April, 2003. The selection was made from the neonatology register list in which is recorded the mother's name, birth weight, sex and birth date. Birth weight was the selection criterion for recruiting infants. Invitation letters were sent to parents of 112 infants with BW <2,500 g, and 159 with $\mathrm{BW}=2,500 \mathrm{~g}$. Among those with BW <2,500 g, 71 (63.39\%) attended and 10 were excluded ( 2 full terms with $\mathrm{BW}<2,500$ $\mathrm{g}$ and 2 with somatic malformations). Among those with BW =2,500 g, 67 (42.14\%) attended and 6 were excluded (3 preterms and 3 were large for gestational age). This study was conducted at the Neurology Department of the State University of Campinas (UNICAMP). The research project was approved by the Ethics in Research Committee of the State University of Campinas and written informed consent was obtained from the parents or guardians.

\section{Inclusion Criteria}

Inclusion criteria for the study group were: $\mathrm{BW}<2,500$ g, preterm birth, i.e., with gestational age under 37 weeks, adequate or small for gestational age (AGA or SGA, respectively) and age between 18 and 35 months at the moment of dental examination. Controls were NBW full-term children (BW =2,500 g and gestational age $\geq 37$ and $\leq 41$ weeks) and AGA. Children with genetic syndromes and malformations diagnosed in the neonatal period were excluded. For preterm infants, corrected age was considered, i.e., chronological age reduced by the number of weeks born before 40 weeks of gestation ${ }^{6}$.

\section{Clinical Examination}

Dental examinations were performed at the Center of Pediatric Investigation (CIPED, UNICAMP) by one of the authors (KMDF), before collecting retrospective medical history. Parents answered a query regarding breastfeeding and/or nursing bottle patterns, previous dental trauma, dietary habits, toothbrushing frequency and medication taken. Preventive dental instructions were given thereafter.

In order to avoid masking of defects by dental plaque, teeth were cleaned with a toothbrush ${ }^{15}$. Teeth were evaluated under artificial light using a dental mirror and dental probe without previous drying. Evaluations were undertaken in the presence of the parent or guardian, with the children seated in front of the researcher. Dental examination was performed in accordance with FDI criteria (modified DDE Index $)^{7}$. A tooth was considered erupted if any portion of the crown had penetrated the mucosa. If more than $2 / 3$ of the tooth surface was restored, decayed or fractured the tooth was considered excluded. A single defect measuring less than $1 \mathrm{~mm}$ in diameter was not recorded. In case of doubt about the existence of a defect, it was scored as normal. The buccal, lingual and occlusal surfaces were examined. When enamel defects were diagnosed, their type and extent were noted. Hypoplasias had the localization registered. Opacities were differentiated from white spot carious lesions based on color, texture, demarcation and relationship to gingival margin ${ }^{15}$. The number of teeth present was also registered. The percentages of teeth affected by DDE were computed by dividing the number of teeth presenting the defect by the total number of teeth present. When permitted, photographs were taken.

\section{Medical History}

Maternal and neonatal medical histories were obtained from hospital records (CAISM - UNICAMP). The data collected retrospectively included the following independent variables: a) Maternal history: hypertension during pregnancy, urinary tract infection, antibiotics, antepartum hemorrhage, premature placental displacement, preterm labor, acute fetal suffering; b) Neonatal history: gender, gestational age, birth weight, $1^{\text {st }}$ and $5^{\text {th }}$ minute Apgar score, sepsis, intraventricular hemorrhage, respiratory distress syndrome, cerebral ultrasound and neurological examination at discharge. The dependent variable was DDE.

\section{Statistical Analysis}

The data were analyzed using SPSS for Windows version 11.0 (SPSS Inc, Chicago, IL, USA) and SAS System for Windows version 8.02 (SAS Institute Inc, 1999-2001, Cary, NC, USA). Chi-square test and Fisher's exact test, wherever appropriate, were used for data analysis. The significance level was set at 0.05 .

\section{RESULTS}

\section{Demography of Subjects}

Table 1 shows the characteristics of the study group ( $n=61$ infants) and control group ( $n=61$ infants). Among the group of preterms, 16 (26.2\%) had extremely low birth weight ( $<1,000$ g), 22 (36.1\%) had VLBW $(<1,500 \mathrm{~g})$ and $23(37.7 \%)$ had LBW $(<2,500 \mathrm{~g})$.

In the preterm group, 24 (39.3\%) children were SGA and 37 (60.7\%) were AGA. All infants born full term were AGA.

\section{Prevalence of Enamel Defects}

As shown in Table 2, significantly more preterm infants presented DDE than the full terms $(\mathrm{p}<0.001)$. Among preterms, 35 (57.4\%) children had some type of DDE, opacities were present in 32 (52.5\%) and hypoplasia in 13 (21.3\%). Of the 61 controls examined, 15 (24.6\%) presented DDE on at least one deciduous tooth, 15 (24.6\%) had opacities and only 2 (3.3\%) infants presented hypoplasia, these two children also presented opacities. 
TABLE 1- Demographic data of the subjects enrolled in the study

\begin{tabular}{lll}
\hline & Preterm & Term \\
\hline Boys (\%) & $32(52.5 \%)$ & $32(52.5 \%)$ \\
Girls (\%) & $29(47.5 \%)$ & $29(47.5 \%)$ \\
Mean birth weight (g \pm SD) & $1352.79 \pm 391.43$ & $3114.26 \pm 332.46$ \\
(Range) & $(515-2475)$ & $(2500-3580)$ \\
Mean gestational age (weeks \pm SD) & $30.7 \pm 2.7$ & $39.4 \pm 1.2$ \\
(Range) & $(25.1-36.7)$ & $(37.1-41.9)$ \\
Mean age at exam (months \pm SD) & $27.75 \pm 4.17$ & $32.97 \pm 3.91$ \\
(Range) & $(18-34)$ & $(21-35)$ \\
Mean age at exam (months \pm SD) & $27.75 \pm 4.17$ & $32.97 \pm 3.91$ \\
(Range) & $(18-34)$ & $(21-35)$ \\
\hline
\end{tabular}

TABLE 2- Enamel defects in deciduous dentition in children born preterm with low birth weight compared to full-term controls

\begin{tabular}{llllll}
\hline & & Preterm & Term & p value* & OR (95\% Cl) \\
\hline \multirow{2}{*}{ Hypoplasia } & present & $13(21.3 \%)$ & $2(3.3 \%)$ & 0.002 & $7.99(1.59-54.04)$ \\
& absent & $48(78.7 \%)$ & $59(96.7 \%)$ & & $3.38(1.47-7.88)$ \\
Opacity & present & $32(52.5 \%)$ & $15(24.6 \%)$ & 0.002 & $4.13(1.78-9.66)$ \\
& absent & $29(47.5 \%)$ & $46(75.4 \%)$ & & $<0.001$ \\
\hline
\end{tabular}

* Chi square test. DDE = developmental defects of enamel.

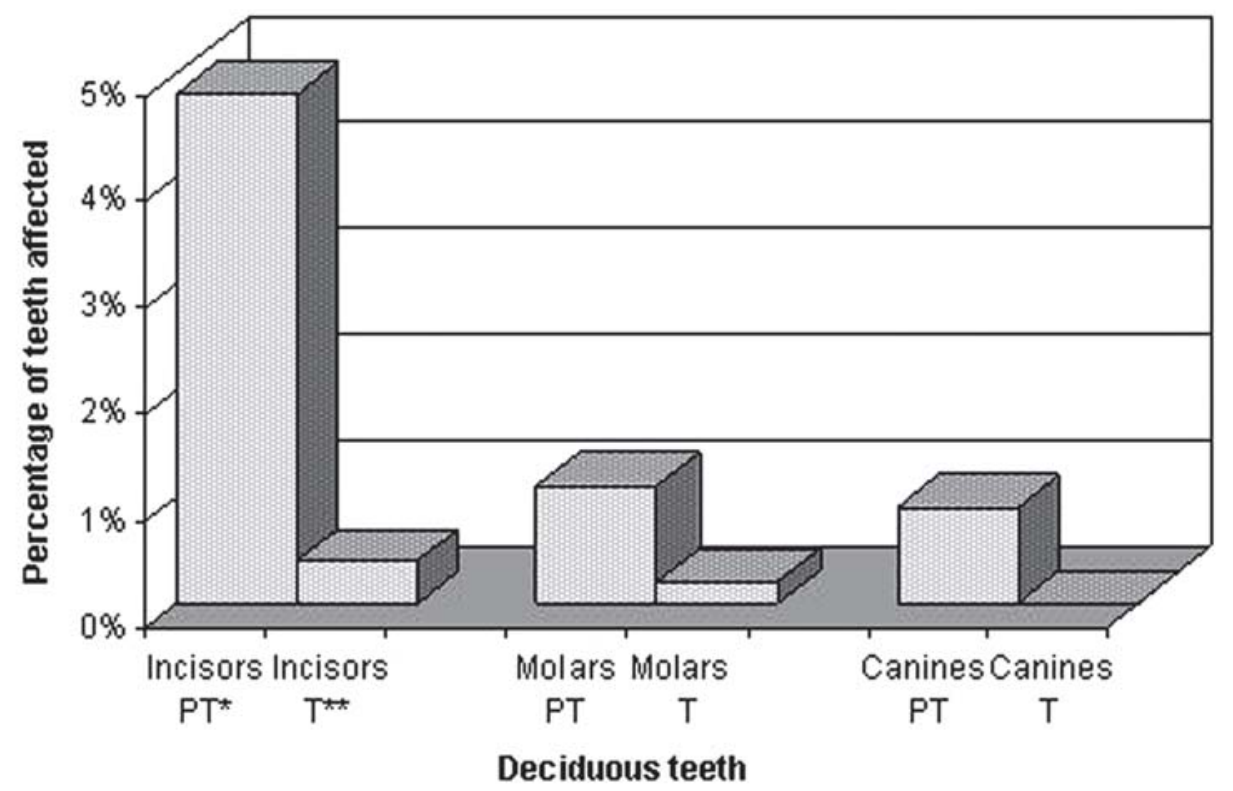

\section{*Preterm group *Term group}

FIGURE 1- Percentage of incisors, molars and canines of the preterm and full-term groups affected by hypoplasia according to number of teeth examined 
In the preterm group, a total of 1073 teeth were examined, of which $4(0.4 \%)$ were excluded due to extensive caries and/or fractures. Regarding the total of 1069 teeth that were considered for the study, 106 (9.9\%) teeth presented DDE and 29 (2.7\%) had hypoplasia. In the full-term group, 1173 teeth were examined and 24 (2\%) were excluded. In relation to the total of 1149 teeth that were considered in the study, 35 (3\%) teeth presented DDE and only 4 (0.3\%) were affected by hypoplasia.

\section{Distribution of Hypoplasia}

Hypoplasia was more frequent in the maxillary arch (5.1\%, 27 teeth of the 532 examined) of preterm infants than in the lower arch $(0.4 \%, 2$ teeth of the 537$)$, with a statistically significant difference $(\mathrm{p}<0.001$, chi square test). Although hypoplasia was slightly more frequent in the maxillary arch $(0.4 \%, 2$ teeth out of 565 examined) than in the lower arch $(0.2 \%, 1$ tooth out of 584$)$ of term children, the difference was not significant ( $p=0.6$, Fisher's exact test). The percentages and distribution of tooth series affected by hypoplasia are shown in Figure 1. In the group of preterm infants, 480 incisors, 372 molars and 217 canines were examined: 23 (4.8\%) incisors, 4 (1.1\%) molars and 2 (0.9\%) canines presented hypoplasia. In the term group, 478 incisors, 436 molars and 235 canines were examined: 2 incisors $(0.4 \%), 1(0.2 \%)$ molar and 0 canine showed hypoplasia. The difference was only significant among incisors ( $<<0.001$, chi square)

\section{Association of Prenatal and Neonatal Variables with Hypoplasia}

Table 3 presents the prenatal and neonatal variables present among those infants that had hypoplasia.

In the group of children born preterm, the results obtained for the association between hypoplasia and the maternal prenatal independent variables hypertension, urinary tract infection, antepartum hemorrhage, premature placental displacement, preterm labor and antibiotics taken during pregnancy were not statistically significant. When associations between the different neonatal independent variables and dependent variable hypoplasia were made, the following proved statistically significant: respiratory distress syndrome and neurological examination at discharge with an altered result (Table 4). Although the associations with intraventricular hemorrhage ( $p=0.06$, Fisher exact test) and sepsis ( $p=0.07$, Fisher's exact test) were not significant they may indicate a trend. In the term group, the associations

TABLE 3- Description of variables present for children with hypoplasia

\begin{tabular}{|c|c|c|c|c|}
\hline \multirow{3}{*}{$\begin{array}{l}\text { Variables } \\
\text { Prenatal }\end{array}$} & \multicolumn{4}{|c|}{ Groups } \\
\hline & \multicolumn{2}{|c|}{ Preterm } & \multicolumn{2}{|c|}{ Term } \\
\hline & $\mathbf{n}$ & $\%$ & $\mathbf{n}$ & $\%$ \\
\hline Preterm labor & 8 & 61.5 & 0 & - \\
\hline Hypertension & 7 & 53.8 & 1 & 50 \\
\hline Acute fetal suffering & 4 & 30.8 & 1 & 50 \\
\hline Urinary tract infection & 3 & 23.1 & 1 & 50 \\
\hline Antibiotics & 3 & 23.1 & 0 & - \\
\hline Premature placental displacement & 2 & 15.4 & 0 & - \\
\hline Antepartum hemorrhage & 2 & 15.4 & 0 & - \\
\hline \multicolumn{5}{|l|}{ Neonatal $n \quad \% \quad n \quad \%$} \\
\hline Male & 8 & 61.5 & 1 & 50 \\
\hline Female & 5 & 38.5 & 1 & 50 \\
\hline Small for gestational age & 5 & 38.5 & 0 & - \\
\hline Adequate for gestational age & 8 & 61.5 & 2 & 100 \\
\hline $1^{\text {st }}$ Apgar score $<7$ & 9 & 69.2 & 2 & 100 \\
\hline $5^{\text {th }}$ Apgar score $<7$ & 0 & - & 0 & - \\
\hline Sepsis & 6 & 46.2 & 1 & 50 \\
\hline Intraventricular hemorrhage & 4 & 30.8 & 0 & - \\
\hline Respiratory distress syndrome & 12 & 92.3 & 0 & - \\
\hline Cerebral ultrasound (with alteration) & 4 & 30.8 & 0 & - \\
\hline $\begin{array}{l}\text { Neurological examination at discharge } \\
\text { (with alteration) }\end{array}$ & 8 & 61.5 & 1 & 50 \\
\hline
\end{tabular}


TABLE 4- Association between enamel hypoplasia, respiratory distress syndrome and neurological examination at discharge in preterm children

\begin{tabular}{|c|c|c|c|c|c|}
\hline & & $\begin{array}{l}\text { Hypoplasia } \\
\text { present }\end{array}$ & $\begin{array}{l}\text { Hypoplasia } \\
\text { absent }\end{array}$ & $p$ value* & OR (95\% Cl) \\
\hline \multirow[t]{2}{*}{$\begin{array}{l}\text { Respiratory distress } \\
\text { syndrome }\end{array}$} & present & 12 (92.3\%) & $26(54.2 \%)$ & 0.002 & $\begin{array}{c}10.15 \\
(1.19-225.58)\end{array}$ \\
\hline & absent & $1(7.7 \%)$ & 22 (45.8\%) & & \\
\hline \multirow[t]{2}{*}{$\begin{array}{l}\text { Neurological } \\
\text { examination** }\end{array}$} & altered & $8(61.5 \%)$ & $8(17 \%)$ & 0.003 & $\begin{array}{c}7.8 \\
(1.70-38.21)\end{array}$ \\
\hline & normal & $5(38.5 \%)$ & 39 (83\%) & & \\
\hline
\end{tabular}

* Fisher's exact test ** 1 missing value

between the independent variables and hypoplasia were not significant.

\section{Previous Preventive Dental Guidance}

When parents were questioned about previously received preventive dental guidance, 44 (72.1\%) in the preterm group answered that they had never received any sort of dental counseling related to their children. In the control group 50 (82 \%) also answered negatively.

\section{DISCUSSION}

The optimum time to evaluate DDE is soon after tooth eruption due to the lack of stability of these findings, which can be lost by dental trauma, attrition or caries ${ }^{3,15}$. In order to minimize the loss of data, the children of the present study were between 18 and 35 months of age at the moment of dental examination. It is worth remarking that in both groups of the present study only a few teeth were excluded due to extensive caries. To avoid misleading results when comparing preterms and full terms, the corrected age was considered for infants born preterm.

Previous investigations have indicated a high prevalence of DDE in preterm and low birth weight children ranging from 20 to $96 \%^{1,10,11,18}$, with the highest frequency in very low birth weight children.

Despite limitations in comparing studies due to methodological differences, the current study found a statistically significant higher prevalence of defects in preterms in agreement with earlier reports. This paper contributes to prevalence data of enamel defects in Brazil since few studies have examined DDE in Brazilian preterm infants ${ }^{4}$.

In accordance with other studies ${ }^{1,10}$, hypoplasia was more frequent in the maxillary arch of preterm infants than in the lower arch, with a statistically significant difference. In term children, the difference was not significant. In the group of preterms, incisors were the most affected teeth by hypoplasia followed by molars and canines, which agrees with the findings of Fearne ${ }^{8}$. Aine and Funakoshi also found enamel defects mainly in maxillary incisors ${ }^{1,9}$. According to Lai, et al., molars were the most frequently affected teeth by hypoplasia ${ }^{11}$. In the present study, the young age of examination minimized the loss of findings but, on the other hand, in some infants second molars were not yet erupted. Evaluation at a more advanced age could reveal a higher frequency in molars. It is interesting to note that the pattern of frequency of hypoplasia seems to be associated with the chronology of calcification of teeth. Deciduous maxillary incisors are the first teeth to start calcification, which occurs between the third and fourth month of intrauterine life ${ }^{2}$. Amelogenesis of deciduous incisors is nearly completed at term birth, while crown development of deciduous canines and molars is still far from completion ${ }^{2,5}$.

Since the birth at the CAISM-UNICAMP was an inclusion criterion for the study group and controls, the authors had the full hospital records for both groups at disposal, making the analysis of etiological factors possible. The association between hypoplasia and prenatal variables was not significant statistically. Although many systemic factors have been associated with enamel hypoplasia, it is difficult to isolate the relative importance of each because they may be concurrent ${ }^{19}$. Seow, et al. ${ }^{1}$ outlined that mineral deficiency could act as a central mechanism underlying systemic disturbances, whereas Aine, et al. ${ }^{19}$ found that mineral supplementation did not reduce the prevalence of DDE. The neonatal variable respiratory distress syndrome when associated with hypoplasia was statistically significant, which is in agreement with the study of Johnsen ${ }^{10}$. Yet many reports have investigated etiologic systemic factors, no study has made the association with a neonatal finding such as neurological examination at discharge. An altered result is this exam may indicate that the newborn is prone to present neurological disorders.

In the term group, associations were not significant probably due to the small number of full-term children that presented hypoplasia. 
Hypoplasia has been considered a significant predictor of dental caries ${ }^{12,13,14,20,21}$. Lai, et al. ${ }^{11}$ found that mild enamel defects, such as opacities without hypoplasia, did not increase caries prevalence, but severe enamel hypoplasia was strongly associated with enamel decay ${ }^{11}$. Fearne, ${ }^{8}$ found a lower caries prevalence in the study group, but stated that this finding may be associated with the fact that the LBW infants were of higher social class and took fluoride supplements. Preterm infants have a higher prevalence of hypoplasia that may predispose to plaque accumulation and tooth decay ${ }^{20}$. In our study group, $70.1 \%$ of the parents affirmed never having received any sort of preventive dental counseling. Therefore, the results of the present study reinforce the importance of preventive dental measures directed towards preterm infants in order to prevent dental caries.

\section{CONCLUSIONS}

LBW preterm infants presented a higher prevalence of hypoplasia than NBW controls. The most affected deciduous teeth by hypoplasia were maxillary incisors. There was no significant association with prenatal variables. Among neonatal variables, there was a significant association with respiratory distress syndrome and neurological examination at discharge with an altered result.

\section{REFERENCES}

1- Aine L, Backström MC, Mäki R, Kuusela AL, Koivisto AM, Ikonen RS et al. Enamel defects in primary and permanent teeth of children born prematurely. J Oral Pathol Med. 2000;29:403-9.

2- Berkovitz BKB, Holland GR, Moxham BJ. Oral anatomy, embryology and histology. $3^{\text {rd }}$ ed. Chicago: Mosby; 2002.

3- Bhat M, Nelson KB, Swango PA. Lack of stability in enamel defects in primary teeth of children with cerebral palsy or mental retardation. Ped Dent. 1989;11(2):118-20.

4- Caixeta FF, Correa MSNP. Os defeitos do esmalte e a erupção dentária em crianças prematuras. Rev Assoc Med Bras. 2005;51(4):195-9.

5- Dmytraczenko-Franco KM, Moura-Ribeiro MVL. Defeitos de desenvolvimento do esmalte em crianças pré-termo e com distúrbios neurológicos. Temas sobre desenvolvimento. 2005;14(80-81):22-5.

6- Engle WA. American Academy of Pediatrics Committee on Fetus and Newborn. Age terminology during perinatal period. Pediatrics. 2004 Nov;114(5):1362-4.

7- FDI Commission on Oral Health, Research and Epidemiology. A review of the developmental defects of enamel index (DDE index). Int Dent J. 1992;42(6):411-26.

8- Fearne JM, Bryan EM, Brook AH. Enamel defects in the primary dentition of children born weighing less than 2000g. Br Dent J. 1990;168:433-7.

9- Funakoshi Y, Kushida Y, Hieda T. Dental observations of low birth weight infants. Ped Dent. 1981;3(1):21-5.
10- Johnsen D, Krejci C, Hack M, Fanaroff A. Distribution of enamel defects and the association with respiratory distress in very low birthweight infants. J Dent Res. 1984;63(1):59-64.

11- Lai PY, Seow WK, Tudehope DI. Enamel hypoplasia and dental caries in very-low birthweight children: a case-controlled, longitudinal study. Ped Dent. 1997;19(1):42-9.

12- Lunardelli SE, Peres MA. Prevalence and distribution of developmental enamel defects in the primary dentition of pre-school children. Braz Oral Res. 2005;19(2):144-9.

13- Milgrom P, Riedy CA, Weinstein P, Tanner ACR, Manibusan L, Bruss J. Dental caries and its relationship to bacterial infection, hypoplasia, diet, and oral hygiene in 6- to 36- month-old children. Community Dent Oral Epidemiol. 2000;28:295-306.

14-Ribeiro AG, Oliveira AF, Rosenblatt A. Early childhood caries: prevalence and risk factors in 4-year-old preschoolers in João Pessoa, Paraíba, Brasil. Cad Saude Publica. 2005;21(6):1695-700.

15- Seow WK. Clinical diagnosis of enamel defects: pitfalls and practical guidelines. Int Dent J. 1997;47(3):173-82.

16- Seow WK. Enamel hypoplasia in the primary dentition: a review. J Dent Child. 1991;58(6):441-52.

17- Seow WK, Brown JP, Tudehope DI, O’Callaghan M. Developmental defects in the primary dentition of low birth-weight infants: adverse effects of laryngoscopy and prolonged endotracheal intubation. Ped Dent.1984;6(1):28-31.

18- Seow WK, Humphrys C, Tudehope DL. Increased prevalence of developmental defects in low birth-weight, prematurely born children: a controlled study. Ped Dent. 1987;9(3):221-5.

19- Seow WK, Masel JP, Weir C, Tudehope DI. Mineral deficiency in the pathogenesis of enamel hypoplasia in prematurely born, very low birth weight children. Ped Dent. 1989;11(4):297-301.

20- Seow WK, Perham S. Enamel hypoplasia in prematurely-born children: A scanning electron microscopic study. J Pedod. 1990;14(4):235-9.

21- Slayton RL, Warren JJ, Kanellis MJ, Levy SM, Islam M. Prevalence of enamel hypoplasia and isolated opacities in the primary dentition. Ped Dent. 2001;23(1):32-6.

22- World Health Organization (WHO). International Statistical Classification of diseases and related health problems (rev. 10, vols. 1-2;ICD-10). Geneva: WHO; 1992. 